\title{
Neurogenic Pulmonary Edema Following Acute Cerebral Infarction
}

\author{
Moo-Seok Park, MD, Jeong-Min Kim, MD, PhD, Young-Chul Youn, MD, PhD, Oh-Sang Kwon, MD, PhD, and Jae-Han Bae, MD \\ Department of Neurology, Chung-Ang University Hospital, Chung-Ang University College of Medicine, Seoul, Korea
}

Background: Neurogenic pulmonary edema is non-cardiogenic pulmonary edema due to sudden excessive activation of sympathetic system after central nervous system injury. We report an acute cerebral infarction patient who developed neurogenic pulmonary edema requiring intubation and mechanical ventilation care.

Case Report: A 77-year-old Korean woman visited emergency room complaining of sudden onset right side weakness which started one hour ago. She had a history of atrial fibrillation with normal ejection fraction. Neurological examination revealed motor aphasia and right side weakness. Brain computerized tomography angiography showed left middle cerebral artery occlusion without frank ischemic change. Intravenous thrombolytic therapy was considered, but suspended because she suddenly complained of respiration difficulty.

Conclusions: This case suggests that large hemispheric infarction can result in acute onset pulmonary edema which is severe enough to require intubation and to delay thrombolytic treatment.

\section{J Neurocrit Care 2016;9(2):171-173}

Key words: Cerebral infarction; Neurogenic pulmonary edema; Central nervous system; Mechanical ventilator

\author{
Received November 4, 2016 \\ Revised May 27, 2016 \\ Accepted July 14, 2016 \\ Corresponding Author: \\ Jeong-Min Kim, MD, PhD \\ Department of Neurology, Chung- \\ Ang University Hospital, Chung-Ang \\ University College of Medicine, 102 \\ Heukseok-ro, Dongjak-gu, Seoul 06973, \\ Korea \\ Tel: +82-2-6299-3126 \\ Fax: +82-2-6299-1493 \\ E-mail: bellokim1@gmail.com
}

Copyright $\odot 2016$ The Korean Neurocritical Care Society

\section{INTRODUCTION}

Neurogenic pulmonary edema (NPE) is the condition of non-cardiogenic abnormal accumulation of extravascular liquid in lungs due to acute central nervous system (CNS) injury. ${ }^{1}$ Although epileptic seizure, cerebral hemorrhage, meningitis and traumatic brain injury are known to be the major contributors, NPE cases after cerebral infarction are relatively rare. ${ }^{2,3}$ Herein, we described an acute middle cerebral artery infarction patient who experienced respiration difficulty requiring intubation and mechanical ventilation due to NPE.

\section{CASE REPORT}

A 77-year-old Korean woman visited emergency room complaining of sudden onset right side weakness which started one hour ago. She had been previously diagnosed as lone atrial fibrillation with normal heart rate. Initial blood pressure was measured as 190/100 $\mathrm{mmHg}$, pulse rate of 100 beats/min, body temperature of $36.8^{\circ} \mathrm{C}$, normal respiratory rate with clear lung sound. Neurological examination revealed motor aphasia and right side weakness, with total National Institute Health Stroke Scale of 15. Brain computerized tomography angiography followed by brain magnetic resonance imaging showed left middle cerebral artery occlusion with acute cerebral infarction (Fig. 1A, B). Her laboratory study results were unremarkable.

cc This is an Open Access article distributed under the terms of the Creative Commons Attribution Non-Commercial License (http://creativecommons.org/licenses/bync/4.0) which permits unrestricted non-commercial use, distribution, and reproduction in any medium, provided the original work is properly cited. 

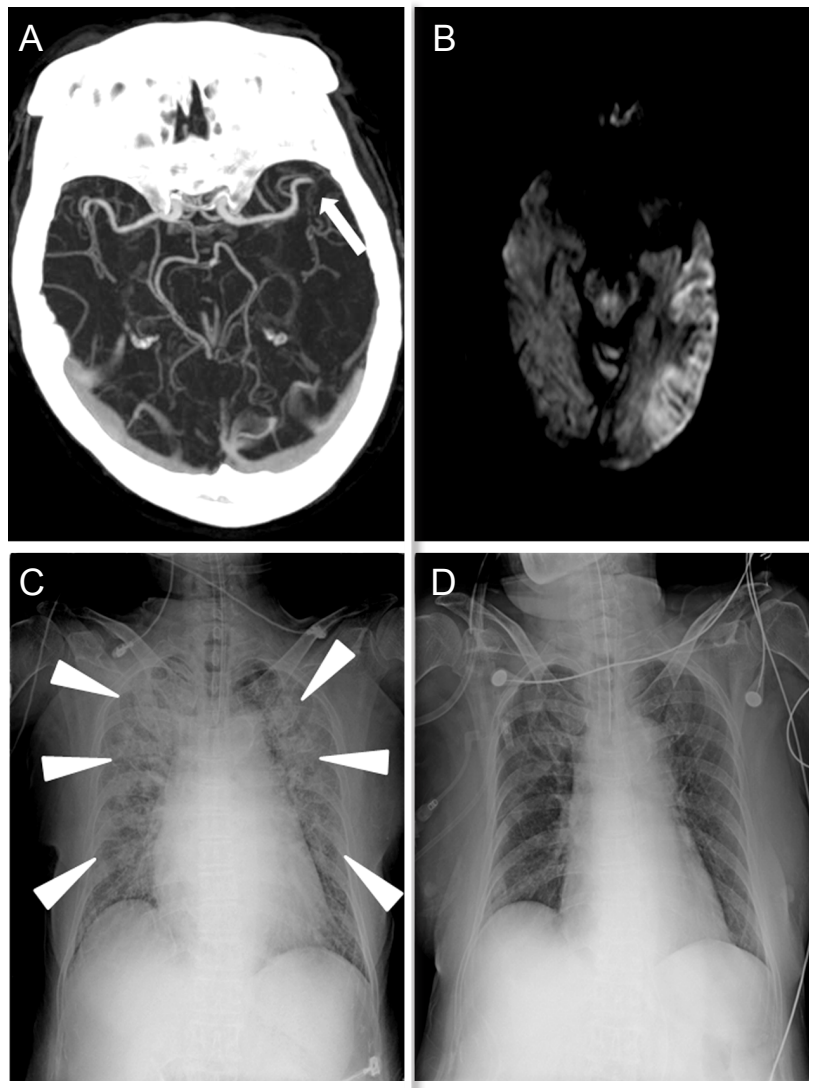

Figure 1. Brain and chest imaging data illustrating neurogenic pulmonary edema after cerebral infarction. Brain CT angiography revealed occlusion of left middle cerebral artery ( $A$, arrow) and diffusion weighted MR imaging showed acute infarctions involving corresponding arterial territory (B). Intravenous thrombolytic treatment was postponed due to sudden onset dyspnea, and followed chest radiography showed acute symmetric interstitial infiltration ( $C$, arrowhead). She was treated by tracheal intubation and mechanical ventilator, and thrombolysis was initiated. Followed chest radiography on hospital day 4 (D) showed minimal interstitial infiltration. CT, computed tomography; $M R$, magnetic resonance.

Intravenous thrombolytic therapy was considered, but suspended because she suddenly complained of difficulty in breathing. Lung auscultation disclosed new rale from whole lung field with lip cyanosis. Jugular venous distention was absent. The oxygen saturation from oximeter monitoring decreased below $85 \%$, necessitating emergent intubation. Arterial blood gas analysis after successful intubation showed elevated carbon dioxide level of $65.7 \mathrm{mmHg}$ (normal range: $32-48 \mathrm{mmHg}$ ), slightly decreased bicarbonate of $21.4 \mathrm{mmol} / \mathrm{L}$ (normal: 22-31 $\mathrm{mmol} / \mathrm{L})$, and low pH with 7.14 (7.35-7.45), suggesting acute respiratory acidosis. The serum levels of cardiac enzyme, brain natriuretic peptide and D-dimer were normal. Followed chest radiography revealed bilateral interstitial infiltrate (Fig. 1C). Thrombolytic treatment with recombinant tissue plasminogen activator $(0.9 \mathrm{mg} / \mathrm{kg})$ was initiated after intubation, and she was transferred to intensive care unit and maintained with mechanical ventilation and intermittent diuretics. Portable echocardiography revealed normal cardiac function without wall motion abnormality. Her respiratory status was rapidly stabilized, and she was weaned from the ventilator on the $4^{\text {th }}$ days after stroke onset (Fig. 1D).

\section{DISCUSSION}

This case describes NPE after acute cerebral infarction due to left middle cerebral artery occlusion, which showed favorable clinical course after intravenous thrombolysis treatment.

The pathophysiology of pulmonary edema following acute brain injury harbors massive adrenergic excitation-induced myocardial dysfunction, altered systemic/pulmonary hemodynamics by sympathetic surge, and pulmonary endothelial integrity disruption. ${ }^{2}$ The possible mechanisms of NPE after cerebral infarction includes abrupt increase of intracranial pressure by large infarction or direct destruction of so called "NPE trigger zones" including insular cortex, hypothalamus or ventrolateral medulla., ${ }^{3,4}$ Sudden disruption of blood supply toward left insular cortex after middle cerebral artery occlusion could be suggested as a possible etiology of NPE in this case. Rapid recovery after successful recanalization by intravenous thrombolysis supports this hypothesis. There has been a previous report describing NPE after left hemispheric infarction involving insular cortex, which was associated with cardiac dysfunction, but rapidly resolved after thrombolytic treatment. ${ }^{4}$ Previous case control study describing pulmonary edema after cerebral infarction showed that brainstem infarction could result in isolated pulmonary edema, whereas suptratentorial hemispheric infarction involving insular cortex showed pulmonary edema with myocardial dysfunction, namely, "stunned myocardium".3

The treatment principal of NPE includes rapid control of the triggering central nervous system insult and supportive treat- 
ment. The clinicians should consider NPE as one of the possible etiologies of sudden respiratory compromise after acute cerebral infarction, when other discernable causes had been excluded. Successful recanalization treatment could result in early improvement of pulmonary edema after acute cerebral infarction.

\section{Acknowledgements}

This work was supported by the Basic Science Research Program through the National Research Foundation of Korea, funded by the Ministry of Education, Science and Technology (grant number: NRF-2014R1A1A2056601).

\section{REFERENCES}

1. Junttila E, Ala-Kokko T, Ohtonen P, Vaarala A, Karttunen A, Vuolteenaho O, et al. Neurogenic pulmonary edema in patients with nontraumatic intracerebral hemorrhage: predictors and association with outcome. Anesth Analg 2013;116:855-61.

2. Davison DL, Terek M, Chawla LS. Neurogenic pulmonary edema. Crit Care 2012;16:212.

3. Probasco JC, Chang T, Victor D, Nyquist P. Isolated pulmonary edema without myocardial stunning in brainstem strokes. / Neurol Trans/ Neurosci 2014;2:1040.

4. Tsui PC, Po HL. Neurogenic pulmonary edema following acute ischemic stroke: a case report and literature review. Neurol Asia 2014;19:195-8. 